\title{
Author Correction: Historical analysis of national subjective wellbeing using millions of
} digitized books

Thomas T. Hills (D), Eugenio Proto (D), Daniel Sgroi (iD) and Chanuki Illushka Seresinhe (D)

Correction to: Nature Human Behaviour https://doi.org/10.1038/s41562-019-0750-Z, published online 14 October 2019.

The Supplementary Information file originally posted was from an earlier version of the paper; it should have been replaced with the final version. The error has been corrected online.

Published online: 14 November 2019

https://doi.org/10.1038/s41562-019-0781-5

(C) The Author(s), under exclusive licence to Springer Nature Limited 2019 